67

EARLY WEANING FROM INCUBATOR AND EARLY DISCHARGE OF PRETERM INFANTS: A RANDOMIZED CLINICAL TRIAL

M. Corsello ${ }^{1}$, E. Zecca², F. Priolo ${ }^{3}$, G. Barone ${ }^{3}$

${ }^{1}$ Neonatology, University Catholic of Sacred Heart, ${ }^{2}$ Catholic of Sacred Heart, ${ }^{3}$ University Catholic of Sacred Heart, Rome, Italy

Objective: Early discharge is to be pursued in preterm infants. The aim of this study was to evaluate the feasibility of an earlier weaning from incubator in preterm infants, and its impact on an earlier discharge.

Methods: This prospective randomized study included preterm infants with birth weight $<1600$ grams admitted in our Neonatal Sub-Intensive Ward. 47 infants transferred from incubator to an open crib at $>1600$ grams (ET Early Transition group) were compared with 47 infants transferred from incubator to an open crib at > 1800 grams (ST Standard Transition group). The primary outcome of the study was the length of stay (LOS). Secondary outcomes were the number of infants returned to incubator, growth velocity (GV) in open crib and during the first week at home, the proportion of breastfeeding at discharge and during the first week at home, and the hospital readmission rate.

Results: LOS was significantly shorter in ET than in ST ( $26 \pm 9$ vs $35 \pm 12$ days; $p=0.0001)$. No infants required to be transferred back to the incubator. Only one infants from ST group was readmitted to the hospital during the first week after discharge. GV and breastfeeding rate were similar between the two groups.

Conclusions: This randomized clinical study demonstrates that weaning preterm infants from incubators to an open crib at weight as low as $1600 \mathrm{~g}$ is associated with an early discharge home without apparent adverse effects.

68

\section{CHILDREN'S EXPERIENCES OF ACUTE HOSPITALISATION TO A PAEDIATRIC \\ EMERGENCY AND ASSESSMENT UNIT - A QUALITATIVE STUDY}

\author{
C.S. Jensen \\ Department of Paediatrics, Aarhus University \\ Hospital, Skejby, Aarhus, Denmark
}

Background: An increasing number of children and families have been acutely admitted to hospital the last decades. Contemporary there has been a fall in the length of hospital stay. In order to meet these changes "short stay units" have been developed, such as paediatric emergency and assessment units (PEAU). With these changes in acute paediatric treatment and care it is challenging to maintain the focus on the child. The predominant approach to researching children's experiences has been based on research on children rather than research with children.

Aim: To gain insight into children's experiences of acute hospitalisation to a PEAU.

Methods: Eight children accepted to participate in an interview. The interviews were antecedent by the children's making of drawings about their experiences during their stay at the PEAU. The drawings were intended to function as a doorway into the children's world. Data were analysed using qualitative content analysis.

Findings: The findings were divided into the following themes:

1. The children's understanding of disease, treatment and procedures 2 . The children's experiences of healthcare personnel

\section{The children's experiences of the PEAU}

4. The children's experiences of having their parents present during their time - at the PEAU

Conclusion: This thesis emphasizes the importance of giving children a voice. The main focus in the children's stories were situations where they were the centre of attention, got positive attention or had other experiences which they found to be interesting or fun. This is an important finding as it is contradictory to other studies. 